\title{
Going for the Gold : Quantifying and Ranking Visual Night Sky Quality in International Dark Sky Places
}

\author{
John Barentine, ${ }^{1, *}$ \\ ${ }^{1}$ International Dark-Sky Association, 3223 North First Avenue, Tucson, AZ 85719- USA
}

Received 05 December 2016, Accepted 21 December 2016

\begin{abstract}
Since the invention of electric lighting in the nineteenth century, the steadily increasing use of artificial light at night in outdoor spaces has grown to threaten the integrity of dark night skies and nocturnal terrestrial spaces. The conservation community has gradually come to accept the need to protect natural nighttime darkness, which finds expression in dark sky parks and similar protected areas. As these places begin to reap tangible economic benefits in the form of sustainable 'astrotourism,' the movement to actively protect them gains strength. The International Dark-Sky Association designates Dark Sky Parks and Reserves under a comparative ranking scheme that assigns night sky quality tiers according to a combination of objective and subjective characteristics, but shortcomings in the consistency of these ratings exist that undermine the consistency and reputation of the designation program. Here we consider potential changes to the qualification regime to make the ratings system more robust for the benefit of future designations.
\end{abstract}

Keywords: Astrotourism, Conservation, Parks and protected areas

\section{Introduction}

Access to naturally dark night skies is threatened on a global scale as the result of emissions of artificial light into the nocturnal environment; some $80 \%$ of the world and more than $99 \%$ of the U.S. and European populations now live under light-polluted night skies. The visibility of the Milky Way, considered a metric of night sky quality, is impaired by anthropogenic light pollution among one-third of humans worldwide. [1] The loss of the night brings a diversity of known and suspected hazards to wildlife ecology that, in concert with global climate change, presents a new set of challenges to the relationship between humans and the environment. [2] Steady growth of world population and the rapid industrialization of emerging economies underscore the acute nature of both the threat and the need to protect what natural darkness still exists. The International Dark-Sky Association (IDA), a U.S.-based non-governmental organization, offers accreditation through its International Dark Sky Places (IDSP) Program $^{1}$ to protected public and private lands that proactively manage their use of outdoor light at night and educate visitors on the value of natural nighttime darkness.

\footnotetext{
* Barentine, J, Tel.: +1-520-293-3198; fax: +1-520-293-3192.

E-mail address: john@darksky.org

1 http://darksky.org/idsp/
} 


\section{The Program}

\subsection{Goals and Achievements}

The goals of the IDSP Program include encouraging good stewardship of the nocturnal environment in both cities and parks through the promotion of sustainable, night-sky-friendly lighting practices, and raising public awareness of the issue of threatened dark night skies around the world. Attendant to the IDA award is global exposure to the burgeoning astrotourism industry, which brings potential concrete economic development benefits to places that embrace the principles of dark skies conservation. [3,4]

Broadly speaking, two kinds of IDSP awards are given. The first ("Dark Sky Community” and "Dark Sky Friendly Development of Distinction") recognizes the efforts of municipalities and similar political entities in controlling the spread of light pollution through the effective application of public policy and the building of social and political coalitions. The second type of award ("Dark Sky Park”, "Dark Sky Reserve”, and "Dark Sky Sanctuary”) highlights the active protection of legally protected areas such as national parks that retain some degree of natural nighttime darkness.

Both types of award value the role of public outreach and education in raising awareness of the issues of light pollution and dark skies; while Dark Sky Communities focus efforts inward to educate their residents, Parks, Reserves and Sanctuaries direct outreach to visitors and the world beyond the protected area. In all cases, proper attention is paid to the qualities of outdoor night lighting at IDSP sites, with requirements for light warranting and shielding, prevention of overlighting, and spectrum control to minimize the emission of environmentally hazardous short-wavelength light. [5]

Program designations are made on the basis of a written application to IDA demonstrating adherence to a set of published guidelines. Applications undergo a form of peer review from a standing committee of the IDA Board of Directors; final approval is given at the discretion of the Board itself. Accredited IDSPs assume the obligation to report to IDA on an annual basis regarding the state of their night sky quality, ongoing outreach efforts, and changes or improvements to site lighting. As of the start of 2017, 71 IDSPs have been designated in 13 countries (see map, Figure 1), bringing some $62,655 \mathrm{~km} 2$ of land under formal protection for the quality of its natural nighttime environment.

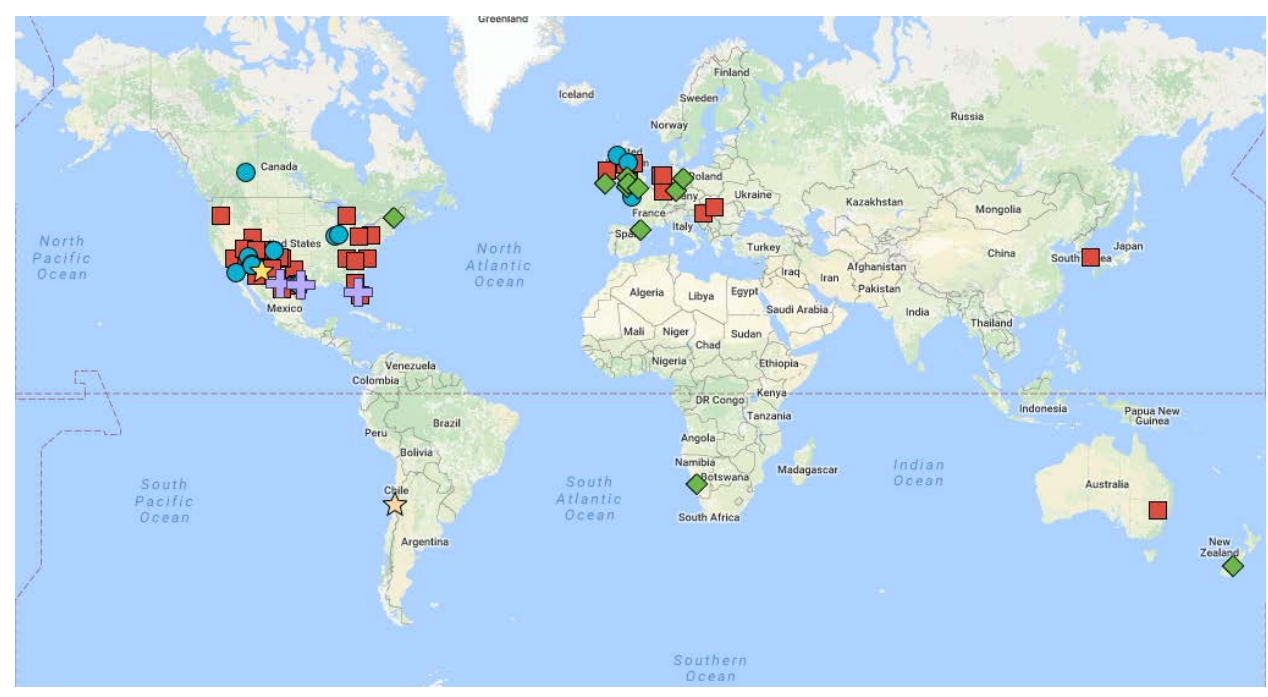

Fig. 1. World map showing the 71 designated IDA International Dark Sky Places as of the beginning of 2017. The symbols are blue circles (Dark Sky Communities), purple crosses (Dark Sky Friendly Developments of Distinction), red squares (Dark Sky Parks), green diamonds (Dark Sky Reserves), and yellow stars (Dark Sky Sanctuaries). 


\subsection{Night Sky Quality Tier Scheme}

IDA Dark Sky Parks, Reserves and Sanctuaries must establish their eligibility for participation in the program in part by submitting night sky luminance measurements. Park and Reserve candidates are currently ranked according to increasing mean zenith luminance in 'Gold', 'Silver' and 'Bronze' tiers. These values, typically obtained using the Unihedron Sky Quality Meter (SQM) [6], are supplemented with horizon photography documenting artificial light domes, narrative descriptions of observed faint night-sky phenomena, and naked-eye limiting magnitude and Bortle Scale [7] estimates. Criteria defining the three tiers are listed in Table 1, adapted from the IDSP Program guidelines.

Table 1. Summary of the subjective and objective qualities characterizing the three IDA International Dark Sky Places sky quality tiers. 'mpsa' stands for magnitudes per square arcsecond, a unit of luminance used mainly by astronomers.

\begin{tabular}{|c|c|c|c|}
\hline Indicator & Gold & Silver & Bronze \\
\hline Philosophy & $\begin{array}{l}\text { Nighttime environments that have } \\
\text { negligible to minor impacts from } \\
\text { light pollution and other artificial } \\
\text { light disturbance, yet still display } \\
\text { outstanding quality night skies and } \\
\text { have superior nighttime lightscapes. }\end{array}$ & $\begin{array}{l}\text { Nighttime environments that have mi- } \\
\text { nor impacts from light pollution and } \\
\text { other artificial light disturbance, yet } \\
\text { still display good quality night skies } \\
\text { and have exemplary nighttime } \\
\text { lightscapes. }\end{array}$ & $\begin{array}{l}\text { Areas not meeting the requirements } \\
\text { of Silver, yet still offering people, } \\
\text { plants, and animals a respite from a } \\
\text { degraded nocturnal environment and } \\
\text { suitable for communicating the issue } \\
\text { of light pollution and connecting } \\
\text { people with the many aspects of the } \\
\text { night sky. }\end{array}$ \\
\hline $\begin{array}{l}\text { Artificial Light } \\
\text { and Skyglow }\end{array}$ & $\begin{array}{l}\text { Typical observer is not distracted by } \\
\text { glary light sources. Light domes are } \\
\text { only dim and restricted to sky close to } \\
\text { horizon. }\end{array}$ & $\begin{array}{l}\text { Point light sources and glary lights do } \\
\text { not dominate nighttime scene. Light } \\
\text { domes present around horizon but do } \\
\text { not stretch to zenith. }\end{array}$ & $\begin{array}{l}\text { Areas with greater artificial light and } \\
\text { skyglow than Silver, but where as- } \\
\text { pects of the natural sky are still visi- } \\
\text { ble. }\end{array}$ \\
\hline $\begin{array}{l}\text { Observable Night } \\
\text { Sky Phenomena }\end{array}$ & $\begin{array}{l}\text { The full array of visible sky phenom- } \\
\text { ena can be viewed- e.g. aurora, air- } \\
\text { glow, Milky Way, zodiacal light, and } \\
\text { faint meteors. }\end{array}$ & $\begin{array}{l}\text { Brighter sky phenomena can be regu- } \\
\text { larly viewed, with fainter ones some- } \\
\text { times visible. Milky Way is visible in } \\
\text { summer and winter. }\end{array}$ & $\begin{array}{l}\text { Many sky phenomena cannot be seen. } \\
\text { Milky Way is seen when pointed out } \\
\text { to the average person, as is the An- } \\
\text { dromeda Galaxy. }\end{array}$ \\
\hline $\begin{array}{l}\text { Nocturnal Envi- } \\
\text { ronment }\end{array}$ & $\begin{array}{l}\text { Area is devoid of obvious lights that } \\
\text { can cause wildlife disorientation. Ar- } \\
\text { tificial light levels are thought to be } \\
\text { below the threshold for plant and an- } \\
\text { imal impact. Ecological processes re- } \\
\text { lated to nocturnality are unaltered. No } \\
\text { lighting atop towers or buildings } \\
\text { within Park boundary. }\end{array}$ & $\begin{array}{l}\text { Areas that have minor to moderate } \\
\text { ground illumination from artificial sky- } \\
\text { glow. Lights that may cause disorienta- } \\
\text { tion to wildlife are distant. Disruption of } \\
\text { ecological processes is minor with no } \\
\text { impairment to plants or wildlife. }\end{array}$ & $\begin{array}{l}\text { Areas with greater nocturnal impact } \\
\text { than Silver, but where ecosystems are } \\
\text { still functional. }\end{array}$ \\
\hline $\begin{array}{l}\text { Naked Eye Limit- } \\
\text { ing Magnitude }\end{array}$ & $\begin{array}{l}\text { Equal or greater than }+6.8 \text { under clear } \\
\text { skies and good seeing conditions }\end{array}$ & $\begin{array}{l}+6.0 \text { to }+6.7 \text { under clear skies and good } \\
\text { conditions }\end{array}$ & $\begin{array}{l}+5.0 \text { to }+5.9 \text { under clear skies and } \\
\text { good seeing conditions }\end{array}$ \\
\hline Bortle Class & $1-3$ & $3-5$ & $5-6$ \\
\hline $\begin{array}{l}\text { Zenith } \\
\text { Luminance }\end{array}$ & $>21.75$ mpsa & 21.74-21.00 mpsa & 20.99-20.00 mpsa \\
\hline
\end{tabular}

The number of designated Dark Sky Parks and Reserves is not evenly distributed among the tiers. Of the 42 Parks and 11 Reserves named to date, 25 (47.2\%) are designated Gold, 26 (49.1\%) Silver, and 2 (3.8\%) Bronze. A histogram of over 30,000 individual SQM-L (narrow acceptance cone) measurements obtained from 33 IDSPs around the world, shown in Figure 2, illustrates the range of night sky luminances encountered over various protected lands considered 'dark' to some degree. 


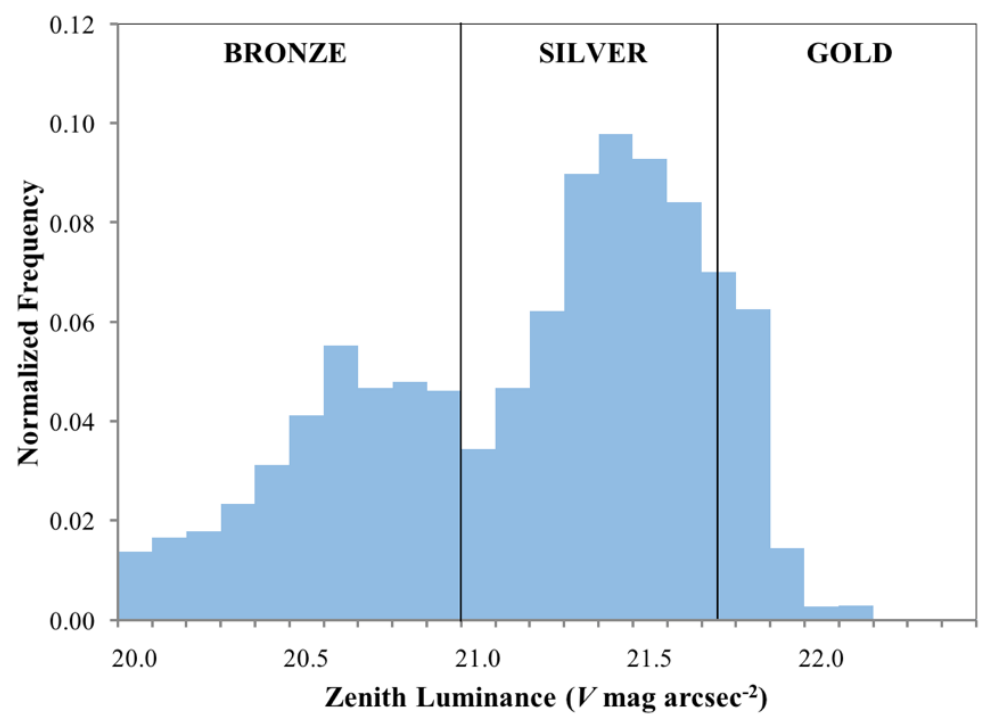

Fig. 2. Normalized frequency histogram of 30,007 SQM-L measurements obtained in IDA Dark Sky Parks, Reserves and Sanctuaries from 2011-2016. Thresholds for the Gold, Silver and Bronze IDA sky quality tiers are indicated.

\section{The Problem}

To properly assess the eligibility of candidate Dark Sky Parks, Reserves and Sanctuaries for IDA accreditation we must gather sufficiently objective night sky brightness information in order to make meaningful comparisons among different sites. Further, for Parks and Reserves, we must establish the proper sky quality tier within the existing scheme. This has proven to be difficult in practice. Reliance on qualitative descriptions of night sky quality and quantitative measurements obtained solely at the zenith anecdotally undercuts the integrity of the Gold/Silver/Bronze tier scheme, which itself has been criticized on the basis of visibility studies. [8] Even the names of the tier labels are problematic, evoking a psychology of winners and losers and creating the potential for misrepresentation of sky conditions by IDSP applicants when site reputation and future tourism revenue are considered to be at stake. Any relative rating scheme for IDSPs involves subjective demarcations of the labels, which results naturally when we attempt to impose arbitrary limits or ranges on empirical observations. As an example, Figure 2 shows the particular difficulty in deciding between awarding the Silver and Gold tiers.

It is increasingly clear that while SQM measurements reliably characterize sky luminances in the presence of significant skyglow from anthropogenic light pollution, their reliability breaks down in situations where there is little or no artificial skyglow. [9] In those circumstances the temporally variable intensity of airglow often dominates, and in all cases the zenith luminance is at best a quasi-periodic function of time. Furthermore, although zenith luminance measurements offer better inter-comparability of different sites, they fail to account for light domes along the horizon that may significantly impact visibility over a large fraction of the sky. Thus, while the SQM is valuable in assessing light-polluted locations, its value is compromised in places that are naturally very dark.

We are left with remarkably fundamental questions unanswered in the context of natural nighttime landscape protection: What is a 'dark sky,' and how do we describe the quality of 'darkness'? And two specific programmatic needs have emerged: first, to amend or replace the current tier system according to our best understanding of human visual perception of the night sky and the various natural and artificial light sources that influence it; and second, to develop low-cost, readily deployable best-practice methods and data collection protocols for characterizing and monitoring night sky quality. 


\section{Potential Solutions}

\subsection{Improved Methods to Measure Night Sky Luminance}

The problem we face is both one of measurement and of deciding which things to measure. It seems clear that we can no longer rely solely on point measurements made with the SQM(-L) at the zenith as our main source of information on the conditions of nighttime darkness in Dark Sky Places. Several potential solutions to the problem exist, all of which lead toward a holistic approach to measuring the brightness of the entire night sky.

Grids of SQM-L measurements taken around the sky may be interpolated to produce crude all-sky luminance maps [10], but they lack spatial resolution of individual light domes. Progress has been made in developing calibrated all-sky camera systems that provide information on the spatial distribution of both natural and artificial sources of light and the gradient of sky luminance [11,12,13,14,15,16,17]; however, these systems are generally expensive to procure and often require expertise to properly operate. Another option is to combine zenith SQM-L measurements with uncalibrated horizon photography; given that most of the artificial sky luminance observed toward the zenith originates from ground sources within $\sim 25 \mathrm{~km}$ of a given location [18], this method can help identify the nearest problematic sources to target for mitigation. Table 2 summarizes the different approaches and the benefits and drawbacks of each:

Table 2. Summary of the subjective and objective qualities characterizing the three IDA International Dark Sky Places sky quality tiers.

\begin{tabular}{lll}
\hline \multicolumn{1}{c}{ Approach } & \multicolumn{1}{c}{ Advantage } & \multicolumn{1}{c}{ Disadvantage } \\
\hline $\begin{array}{l}\text { Interpolate grids of SQM measure- } \\
\text { ments taken around the sky to produce } \\
\text { crude all-sky luminance maps }\end{array}$ & $\begin{array}{l}\text { Makes use of existing, inexpensive } \\
\text { and widely-available SQM devices }\end{array}$ & $\begin{array}{l}\text { Lacks good spatial resolution of indi- } \\
\text { vidual light domes on the local horizon }\end{array}$ \\
\hline $\begin{array}{l}\text { Use all-sky camera systems to provide } \\
\text { information on the spatial distribution } \\
\text { of both natural and artificial sources } \\
\text { of light }\end{array}$ & $\begin{array}{l}\text { Gives more precise information on } \\
\text { the brightness and extent of light } \\
\text { domes impacting nighttime environ- } \\
\text { ment }\end{array}$ & $\begin{array}{l}\text { Systems are generally expensive to pro- } \\
\text { cure and often require expertise to } \\
\text { properly operate }\end{array}$ \\
\hline $\begin{array}{l}\text { Combine zenith SQM measurements } \\
\text { with uncalibrated horizon photog- } \\
\text { raphy }\end{array}$ & $\begin{array}{l}\text { Involves readily available instru- } \\
\text { ments not requiring special calibra- } \\
\text { tion }\end{array}$ & $\begin{array}{l}\text { Uncalibrated imagery is of limited use } \\
\text { for tracking quantitative changes to } \\
\text { light domes }\end{array}$ \\
\hline
\end{tabular}

There is presently an increasing demand for an affordable, off-the-shelf imagery system for obtaining simultaneous all-sky measurements of night sky luminance for both initial site evaluation and ongoing monitoring. Duriscoe [19] suggests a number of useful metrics that can be extracted from such spatially-resolved sky luminance data; combined with visibility studies, these may lead toward a more robust and objective means of deciding which candidates are best suited for IDA Dark Sky Place recognition.

\subsection{A New Aesthetic Approach}

Another means of solving the problem is to develop new metrics of the human visual experience of dark-sky sites, recognizing that this experience is both quantitative and qualitative in nature. Characterizing IDA Dark Sky Places in terms of their night sky brightness has scientific value, but the program is equally oriented toward aesthetic appreciation of night skies by visitors. One possible improvement on the current tier scheme is to cite a range of statistically likely values on one or more scales. These scales may be intuitive and user friendly. For 
example, the Sky Quality Index (SQI; see Figure 3) is an experimental 1-100 index developed by the U.S. National Park Service that features units of equal aesthetic value. [20]

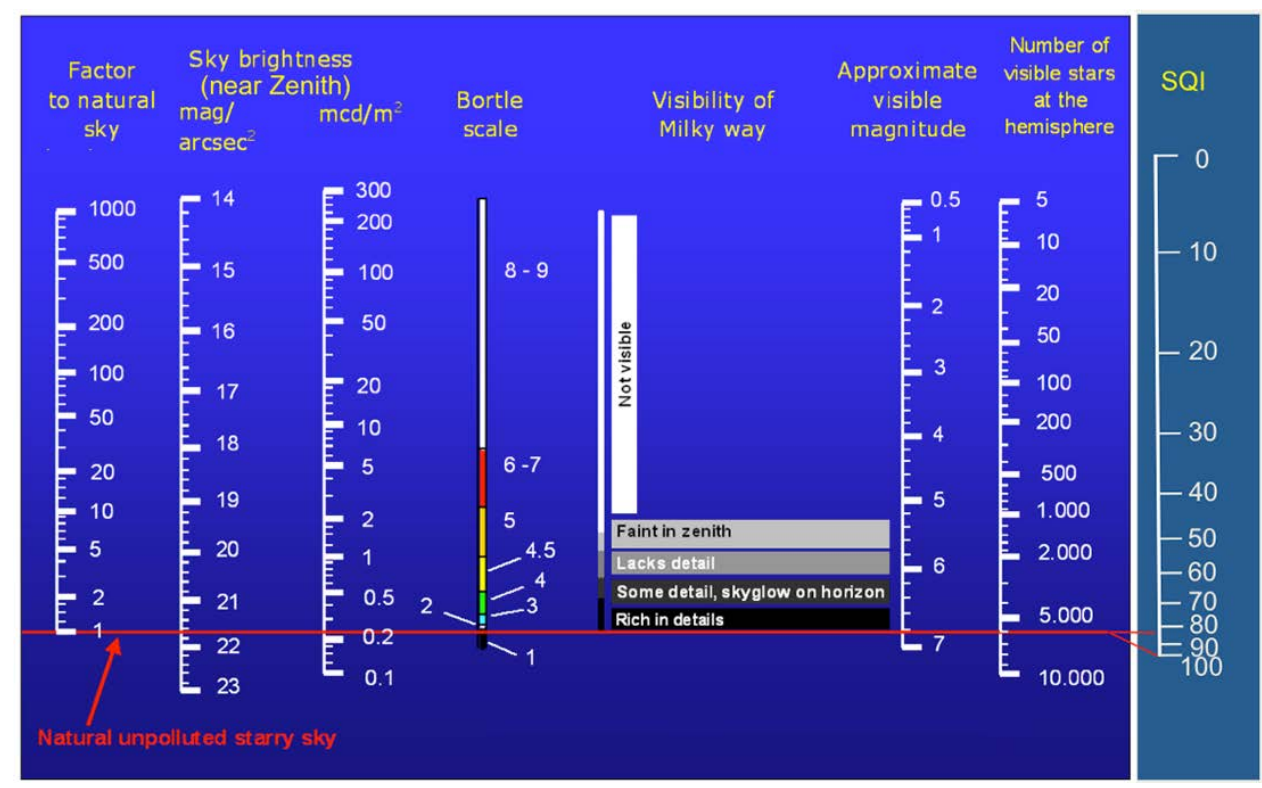

Fig. 3. Nomogram of various sky brightness measures illustrating the U.S. National Park Service Sky Quality Index (SQI) metric. Figure by Henk Spoelstra, used with permission.

Even in the absence of anthropogenic light pollution, a metric such as the SQI is subject to time variability on scales spanning hours to years due to changes in the intensity of airglow and aurorae, atmospheric aerosol optical depth, and other natural factors. It may not be possible to completely capture the 'typical' conditions at a dark sky site through point measurements of a single characteristic. Rather, it may be best to quote a range of typical values on one scale or another, centered on the most probable value, and in which the statistical scatter of long-term measurements indicates the width of the range. Combining a dark-sky quality range with an expression of local historical climate information drives a new type of index that better equips travelers to Dark Sky Parks and Reserves to choose which sites to visit based on the greatest probability of observing the darkest (and clearest) night skies.

\section{Summary}

While the IDA International Dark Sky Places Program has been highly successful in securing protections for the dark night skies over parks and protected areas around the world, a serious deficiency exists in the methods of characterizing the quality of those skies. We have established here the nature of the problem and explained why it is important to solve. We have also briefly examined a variety of approaches to an improved understanding of night sky quality indicators. From this analysis, we conclude that broad metrics such as the existing IDSP quality tiers do not adequately characterize the complexity of night sky conditions from a given location over various timescales, and that further reliance on them may be detrimental to achieving the program's goals. We find there are several ways forward that lead toward alternatives to the existing Gold/Silver/Bronze tier system. It is expected that IDA will announce a new framework for ranking IDSPs by sky brightness along with updated program guidelines in 2017.

\section{References}

[1] Falchi, F., Cinzano, P., Duriscoe, D., Kyba, C. C., Elvidge, C. D., Baugh, K., ... \& Furgoni, R. (2016). The new world atlas of artificial night sky brightness. Science advances, 2(6), e1600377. 
[2] Rich, C., Longcore, T. (2006). Ecological consequences of artificial night lighting. Island Press.

[3] Gallaway, T., Olsen, R. N., \& Mitchell, D. M. (2010). The economics of global light pollution. Ecological Economics, 69(3), 658-665.

[4] Mitchell, D.M., Gallaway, T. (2016(unpublished)). Estimating the Potential Economic Value of the Night Skies Above the Colorado Plateau. U.S. National Park Service white paper.

[5] International Dark-Sky Association. (2010). Visibility, environmental, and astronomical issues associated with blue-rich white outdoor lighting. Tucson-Washington, DC. Available at: http://bit.ly/2gKiEfN.

[6] Cinzano, P. (2005). Night sky photometry with sky quality meter. ISTIL Int. Rep, 9. Available at: http://bit.ly/2gKjGs5.

[7] Bortle, J.E. (2001). Introducing the Bortle Dark-Sky Scale. Sky and Telescope, 60, 126-129.

[8] Crumey, A. (2014). Human contrast threshold and astronomical visibility. Monthly Notices of the Royal Astronomical Society, 442(3), 2600-2619.

[9] Bará, S., Espey, B., Falchi, F., Kyba, C., Nievas Rosillo, M., Pescatori, P., ... \& Wuchterl, G. (2015). Report of the 2014 LoNNe intercomparison campaign. Available at: http://eprints.ucm.es/32989/1/2014_LoNNe_Intercomparison_report.pdf.

[10] Zamorano Calvo, J., Sánchez de Miguel, A., Nievas Rosillo, M., \& Tapia Ayuga, C. (2014). NixNox procedure to build Night Sky Brightness maps from SQM photometers observations. Madrid: Universidad Complutense. 2014. Available at: http://eprints.ucm.es/26982/1/LICA_NixNoxProcedure.pdf

[11] Duriscoe, D. M., Luginbuhl, C. B., \& Moore, C. A. (2007). Measuring night-sky brightness with a widefield CCD camera. Publications of the Astronomical Society of the Pacific, 119(852), 192.

[12] Rabaza, O., Galadí-Enríquez, D., Estrella, A. E., \& Dols, F. A. (2010). All-sky brightness monitoring of light pollution with astronomical methods. Journal of environmental management, 91(6), 1278-1287.

[13] Kolláth, Z. (2010). Measuring and modelling light pollution at the Zselic Starry Sky Park. In Journal of Physics: Conference Series (Vol. 218, No. 1, p. 012001). IOP Publishing.

[14] Aceituno, J., Sánchez, S. F., Aceituno, F. J., Galadí-Enríquez, D., Negro, J. J., Soriguer, R. C., \& Gomez, G. S. (2011). An all-sky transmission monitor: ASTMON. Publications of the Astronomical Society of the Pacific, 123(907), 1076.

[15] Nievas Rosillo M. (2013). Absolute photometry and Night Sky Brightness with all-sky cameras. Madrid: Universidad Complutense. Available at: http://eprints.ucm.es/24626/1/MasterThesis_MiguelNievas_v2.pdf.

[16] Rabaza, O., Aznar-Dols, F., Mercado-Vargas, M. J., \& Espín-Estrella, A. (2014). À new method of measuring and monitoring light pollution in the night sky. Lighting Research \& Technology, 46(1), 5-19.

[17] Dömény and Kolláth. (2017). Intl J of Sust Lighting (in press)

[18] Aubé, M., \& Roby, J. (2014). Sky brightness levels before and after the creation of the first International Dark Sky Reserve, Mont-Mégantic Observatory, Québec, Canada. Journal of Quantitative Spectroscopy and Radiative Transfer, 139, 52-63.

[19] Duriscoe, D. M. (2016). Photometric indicators of visual night sky quality derived from all-sky brightness maps. Journal of Quantitative Spectroscopy and Radiative Transfer, 181, 33-45.

[20] Moore, C., Turina, F., White, J. (2013). Recommended indicators and thresholds of night sky quality for NPS state of the park reports. U.S. National Park Service report. Available at: http://bit.ly/2gD8gUe. 